\title{
VERTEBRAL METASTASES AND SPINAL CORD COMPRESSION
}

By K. Shibasaki, M.D. Ph.D., ${ }^{1}$ C. G. Harper, M.B.B.S., F.R.C.P.A., ${ }^{2}$ G. M. Bedbrook, K.B., O.B.E., O.StJ., Hon. M.D. (W.A.), M.S. (Melb.), D.P.R.M., F.R.C.S., F.R.A.C.S. ${ }^{3}$ and B. A. Kakulas, A.O., M.D. (Hon. Athens), M.D., F.R.A.C.P., F.R.C.Path., F.R.C.P.A. ${ }^{4}$

${ }^{1}$ Department of Orthopaedic Surgery, National Murayama Hospital, 2-37-I Gakuen, Musashimurayama-shi, Tokyo I9o-I2, Fapan. ${ }^{2}$ Department of Neuropathology, Royal Perth Hospital, Box X22I 3 GPO, Perth, Western Australia 6oor. ${ }^{3}$ Department of Orthopaedic Surgery, Royal Perth (Rehabilitation) Hospital, Shenton Park, Western Australia 60o8. ${ }^{4}$ Department of Neuropathology, Royal Perth Hospital and Department of Pathology, University of Western Australia, Nedlands, Western Australia 6009.

Summary. Clinical interest in spinal compression and resultant paraplegia due to metastases has mounted in recent years. This has stimulated attention to the neuropathology of the condition. Fourteen cases of spinal cord compression due to vertebral metastases are compared with over I00 traumatic cases. In the traumatic lesions there is central haemorrhagic necrosis leading to cavitation and gliosis with nerve root regeneration in the late stages. In the metastatic cases, lesions are often peripheral, pie-shaped and are related to vascular factors. The neuropathology of cord necrosis due to metastatic spinal disease is therefore different to trauma. These observations have clinical importance in planning treatment.

Key words: Paraplegia; Metastatic; Spinal Compression.

\section{Introduction}

Compression of the spinal cord or nerve roots is relatively common in patients with vertebral metastatic deposits. Previous reports on this subject generally emphasise the clinical aspects (Alexander, Davis and Field, I956; Botterell and Fitzgerald, I959; Kennady and Stern, I962; Mullan and Evans, I957; Torma, I957). Few give detailed descriptions of the metastatic deposits within the spinal column or of the spinal cord neuropathology (McAlhany and Netsky, I955).

The purpose of the present study is to describe the exact location of the vertebral and epidural metastases and the associated changes in the spinal cord. In addition, the clinical and the neuropathological findings are correlated. This information may influence the clinical management and operative procedures in relation to vertebral metastases and spinal cord compression in the future.

\section{Clinical Material and Methods}

Fourteen cases of spinal cord compression or radiculopathy due to vertebral metastases were examined in the period from November 1975 to December I976 in the Department of Neuropathology, Royal Perth Hospital. Most of these patients were clinically examined by at least one of the authors 
(K. Shibasaki or G. M. Bedbrook) whilst they were in the Royal Perth (Rehabilitation) Hospital.

Most of the spinal specimens were fixed within an hour of death by the injection of 50 to $100 \mathrm{ml}$ of 10 per cent formol-saline into the spinal theca. Later, at formal necropsy, the vertebral column was removed in toto. After a further period of fixation the vertebral laminae were removed and the spinal cord examined in situ within the canal. Careful examination of the meninges, spinal cord, nerve roots and blood vessels was made and photographs and X-rays were taken where appropriate. The spinal cord within its dural sheath was then removed and the vertebral canal inspected. The bony column was then sectioned vertically in the saggital plane. In several instances vertebrae were sectioned in the horizontal plane in order to examine the anatomical relationships between epidural and vertebral metastatic deposits more closely. The dura was then opened and the spinal cord examined. Transverse sections of the spinal cord were made at numerous levels. Specimens for histological examination were taken from any suspected vertebral or epidural metastases and from many levels of the spinal cord with particular emphasis on the region of the clinically documented paralysis. Both frozen section and paraffin blocks were prepared and staining techniques included Haematoxylin and Eosin, Nissl, Weil, Martius Scarlet Blue, Oil Red $O$ and Marchi stains. Glees and Marsland silver impregnations were also performed. Tabulations were made of the distribution of metastatic tumours in the vertebral column and spinal canal in relation to the spinal cord lesions. Complete records for each case were available for cliniconeuropathological correlation.

\section{Results}

\section{Clinical}

Table I summarises the clinical data of the I4 patients, seven males and seven females. Their ages range from i 9 to 79 years although all but two were older than 48 years. Ten of the group were paraplegic and one had an episode of transient tetraparesis. This recovered after spinal traction. The other three patients had radiculopathy (Case 6), cauda equina involvement (Case 9) and low back pain with parasthesia (Case I2). Of the Io paraplegic patients five were clinically complete paraplegia and five were incomplete. There was no characteristic pattern of sensory or motor disturbance in the cases of incomplete paraplegia. The presenting symptoms were pain in I I cases and parasthesia in three cases. Four patients gave no history of symptoms related to their primary tumour when they first presented to hospital.

Table II lists the sites of the primary tumours. The neoplasms most commonly associated with vertebral metastases in this series were carcinoma of lung, breast and colon and multiple myeloma.

The clinical level of spinal cord compression is shown in Table III. Ten of the I4 cases had thoracic cord compression and six of these were in the upper thoracic region $\left(\mathrm{T}_{\mathrm{I}}-6\right)$. Paraplegia or tetraplegia developed suddenly in four cases and within one week of the onset of neurological symptoms in Io of the I I patients. Of the five patients who developed sudden tetraparesis, three were precipitated by minor trauma. Seven 
TABLE I

Clinical, pathological and radiological features

\begin{tabular}{|c|c|c|c|c|c|c|}
\hline $\begin{array}{l}\text { Case } \\
\text { number }\end{array}$ & Sex & Age & $\begin{array}{l}\text { Mode of } \\
\text { onset }\end{array}$ & $\begin{array}{c}\text { Site of } \\
\text { primary tumour }\end{array}$ & $\begin{array}{l}\text { Vertebrae } \\
\text { affected }\end{array}$ & $\begin{array}{l}\text { Survival } \\
\text { (weeks) }\end{array}$ \\
\hline \multicolumn{7}{|l|}{$A_{75.352}$} \\
\hline $\begin{array}{c}I \\
A 75,326\end{array}$ & $\mathrm{~F}$ & 52 & Sudden & Ca. of Cervix & $\mathrm{T}_{2} \& \mathrm{~T}_{3}$ & 17 \\
\hline $\begin{array}{c}\mathrm{A} 75 \cdot 326 \\
2 \\
\text { A76.286 }^{2}\end{array}$ & $\mathrm{~F}$ & 48 & One week & Ca. of Breast & $\begin{array}{l}\text { Multiple-largest } \\
\text { at TIO }\end{array}$ & 8 \\
\hline $\begin{array}{c}3 \\
\text { A } 76.26 \mathrm{I}\end{array}$ & $\mathrm{F}$ & 67 & Sudden & Ca. of Breast & $\begin{array}{l}\mathrm{C}_{2} \\
\mathrm{~T}_{2} \text { to } \mathrm{T}_{5}\end{array}$ & I 6 \\
\hline $\begin{array}{c}4 \\
\text { A } 76.237\end{array}$ & M & 50 & $\begin{array}{l}\text { Sudden } \\
\text { Several }\end{array}$ & Ca. of Lung & $\begin{array}{l}\text { TII \& TI2 } \\
\text { Multiple-largest }\end{array}$ & 22 \\
\hline $\begin{array}{l}5 \\
\text { A } 76.151\end{array}$ & $\mathrm{~F}$ & 79 & days & Ca. of Stomach & $\begin{array}{l}\text { from Tro to Tiz } \\
\text { Nil-Leptomeningeal }\end{array}$ & 2 \\
\hline $\begin{array}{c}6 \\
\text { A } 76.2\end{array}$ & $\mathbf{M}$ & 49 & Slow & $\begin{array}{l}\text { Ca. Larynx } \\
\text { Multiple }\end{array}$ & $\begin{array}{l}\text { carcinoma } \\
\text { Multiple-largest }\end{array}$ & 12 \\
\hline $\begin{array}{c}7 \\
\text { A } 76.36\end{array}$ & $\mathrm{~F}$ & 53 & 4 days & myeloma & $\begin{array}{l}\text { at T8 } \\
\text { Multiple-largest }\end{array}$ & I 6 \\
\hline $\begin{array}{c}8 \\
\text { A76.47 }\end{array}$ & $\mathbf{M}$ & 19 & One week & Osteosarcoma & at $\mathrm{T} 6, \mathrm{~T}_{12} \& \mathrm{~L}_{3}$ & 4 \\
\hline $\begin{array}{c}9 \\
\mathrm{~A}_{7} 6.65\end{array}$ & $\mathrm{~F}$ & 76 & $\begin{array}{l}\text { Slow } \\
\text { Several }\end{array}$ & Ca. of colon & $\mathrm{C}_{5}, \mathrm{~T}_{2} \& \mathrm{~L}_{4}$ & 6 \\
\hline $\begin{array}{c}\text { IO } \\
\text { A76.7 I }\end{array}$ & M & 3 I & days & $\begin{array}{l}\text { Ca. of Lung } \\
\text { Multiple }\end{array}$ & $\mathrm{T}_{2} \& \mathrm{~T}_{3}$ & 6 \\
\hline $\begin{array}{l}\text { I I } \\
\text { A76.I } 63\end{array}$ & $\mathrm{~F}$ & 66 & Sudden & myeloma & TI2 \& L4 & 20 \\
\hline $\begin{array}{c}\text { I } 2 \\
\text { A76.45 I }\end{array}$ & $M$ & 49 & Sudden & Adenocarcinoma & TII \& TI2 & 3 \\
\hline $\begin{array}{c}\text { I } 3 \\
\text { A76.298 }\end{array}$ & $M$ & 59 & 5 days & Ca. of Colon & $\mathrm{C}_{3}, \mathrm{~T}_{4} \& \mathrm{~T}_{5}$ & 3 \\
\hline I 4 & $M$ & 57 & Slow & Ca. of Prostate & $\mathrm{T}_{4} \& \mathrm{~T}_{5}$ & IO \\
\hline
\end{tabular}

TABLE II

Sites of primary tumours

\begin{tabular}{ll}
\hline Carcinoma of lung & 2 \\
Carcinoma of breast & 2 \\
Carcinoma of colon & 2 \\
Carcinoma of prostate & I \\
Carcinoma of cervix & I \\
Carcinoma of larynx & I \\
Carcinoma of stomach & I \\
Multiple myeloma & 2 \\
Osteosarcoma & I \\
Adenocarcinoma (Primary unknown) & I
\end{tabular}


TABLE III

Clinical level of spinal cord or root compression

\begin{tabular}{ll}
\hline Cervical & 2 \\
Upper Th & 6 \\
Lower Th & 4 \\
Lumber & 2 \\
\hline
\end{tabular}

TABLE IV

Result of laminectomy

\begin{tabular}{ll}
\hline Complete recovery & $\mathrm{I}^{\star}$ \\
Improvement of sensory function & $\mathrm{I}$ \\
Unchanged & 5 \\
\hline
\end{tabular}

* This patient had a recurrence within 3 months.

TABLE V

Comparison of survival times (I 4 patients)

\begin{tabular}{lcc}
\hline Survival time & Operative procedure (7) & No operative procedure (7) \\
\hline I month & 2 & 2 \\
2 months & 2 & I \\
3 months & I & I \\
Greater than 3 months & 2 & 3 \\
Mean & I0.3 weeks & I0.4 weeks \\
\hline
\end{tabular}

patients were subjected to laminectomy. Details of these cases are shown in Table IV. Laminectomy was carried out within twenty four hours of the development of paraplegia in only one patient. The results of surgery were poor. Only one of the seven patients made a complete recovery (Case I I). She presented as an incomplete paraplegia below $\mathrm{LI}_{\mathrm{I}}$, but unfortunately three months later at the same level developed complete paraplegia.

The length of survival after the onset of paraplegia was not significantly affected by operative procedures. The mean survival time of about ten weeks for both groups of patients were similar as indicated in Table V.

\section{Macroscopic Pathological Findings}

\section{The Spinal Column}

The largest vertebral metastases were most common in the thoracic spine. One patient (Case 6) presented with lower cervical radiculopathy due to leptomeningeal carcinoma in the absence of vertebral metastases. Twelve patients had metastatic foci in two or more vertebrae and four of these had multiple metastases (Fig. I). With regard to other metastatic foci, nine 


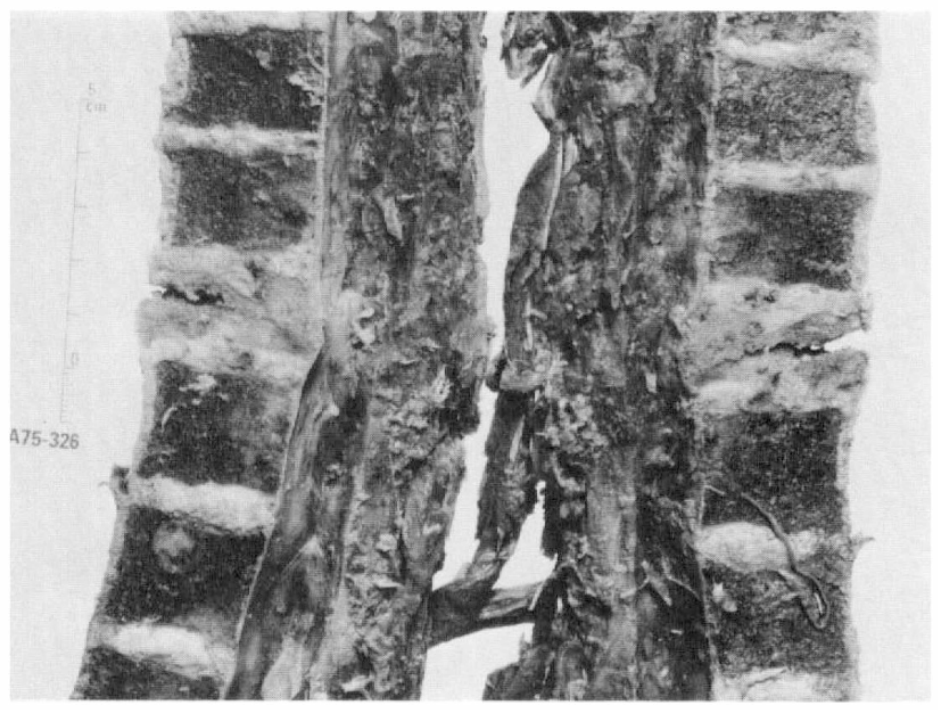

FIG. I

(Case 2, A75.326) Saggital section of vertebral column. Note the numerous metastases in the vertebral bodies. Tro vertebra has collapsed causing an incomplete paraplegia below TI I.

TABLE VI

Localisation of vertebral metastases

\begin{tabular}{lr}
\hline Vertebral body & I3 \\
Pedicle & IO \\
Posterior lamina & 5 \\
Epidural deposit & 4 \\
Leptomeninges & I \\
\hline
\end{tabular}

patients had lung metastases and two had cerebral metastases. Table VI indicates the anatomical localisation of the metastases within the vertebrae at the level of spinal cord or root compression. The vertebral bodies and the pedicles were most commonly involved with extension to the posterior laminae in only five cases. It is noteworthy that three of the four epidural deposits were continuous with vertebral body or pedicle metastases.

At the level of the paraplegia, vertebral bodies were found to be collapsed in nine cases, and two of these were complicated by anterior dislocation of the adjacent vertebrae (Fig. 2). There was instability of the vertebral columns at the level of cord involvement. This instability was particularly noticeable in four of the patients who had undergone laminectomy (Fig. 3). Two other complications were noted in association with laminectomies. Firstly there were dense meningeal adhesions in all seven cases and secondly a cerebrospinal fluid fistula was found in one case. The walls of this fistula were infiltrated by carcinoma. 


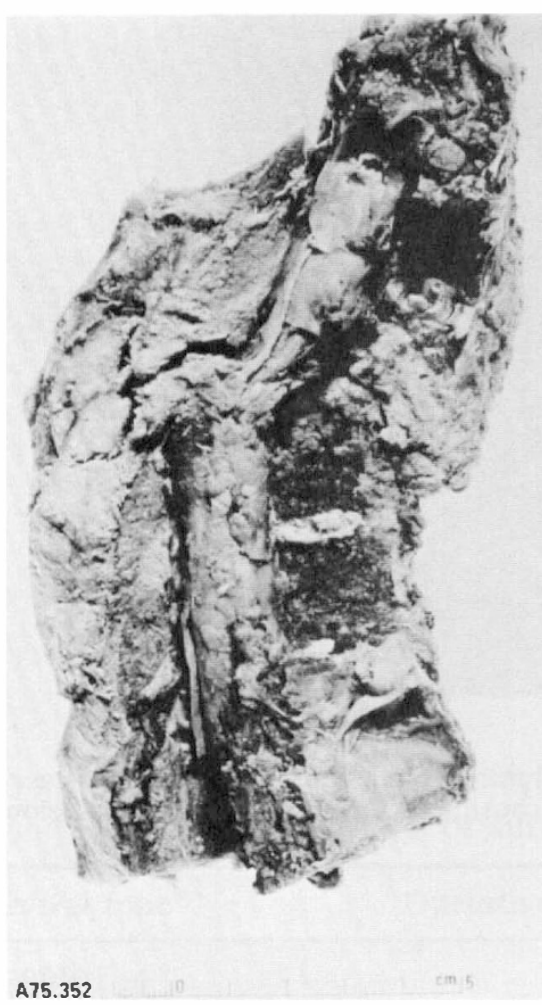

FIG. 2

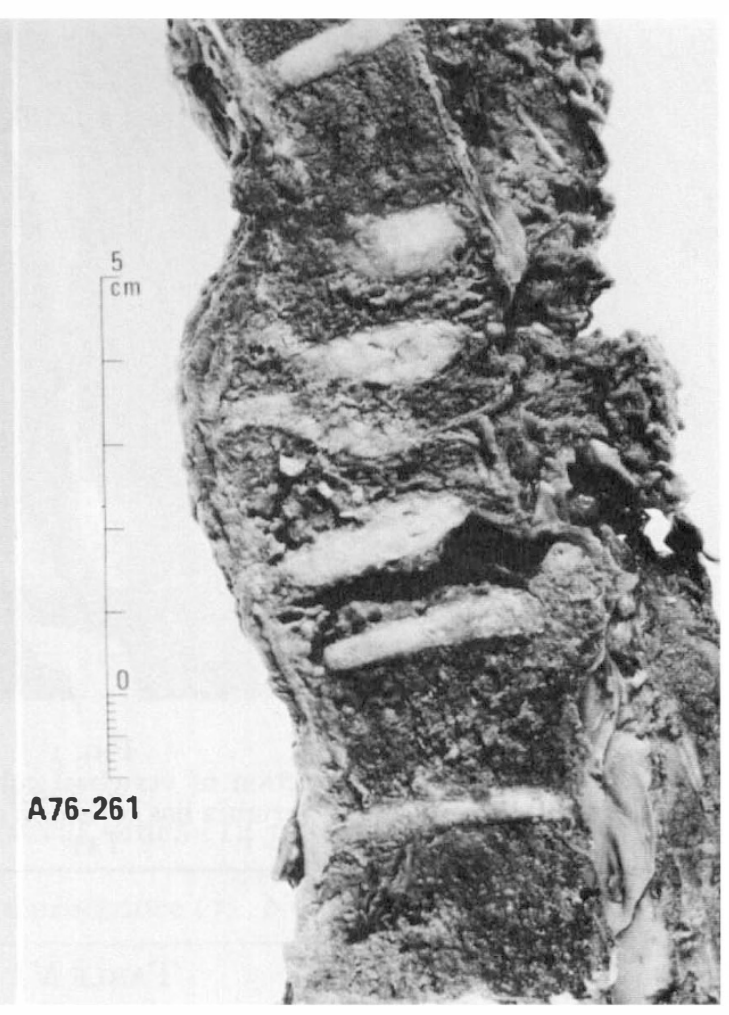

FIG. 3

FIG. 2

(Case I, A75.352) $\mathrm{T}_{2}$ and $\mathrm{T}_{3}$ vertebral bodies are completely replaced by tumour and have collapsed. This is anterior dislocation of the adjacent vertebrae causing spinal cord compression.

FIG. 3

(Case 4, A76.26I) Laminectomy was performed from $T_{2}$ to $T_{5}$. There is collapse of the vertebrae and severe instability of the spine at this level.

\section{Neuropathology}

The macroscopic and microscopic findings of the spinal cord are detailed in Table VII. There was severe softening of the cord adjacent to the compressive lesion in three instances. In ten other cases there was compression with distortion of the spinal cord caused by expansion or collapse of vertebral bodies, pedicles and laminae or epidural deposits. Only one of the four epidural deposits was a solitary lesion, the others being in continuity with vertebral body or pedicle metastases. The epidural deposits were slightly adherent to the dura mater and there was no macroscopic or microscopic evidence of tumour actually infiltrating the dura. One epidural mass was attached to the right $\mathrm{C}_{3}$ nerve root. This was an isolated deposit of adenocarcinoma lying in the epidural space. The 
VERTEBRAL METASTASES

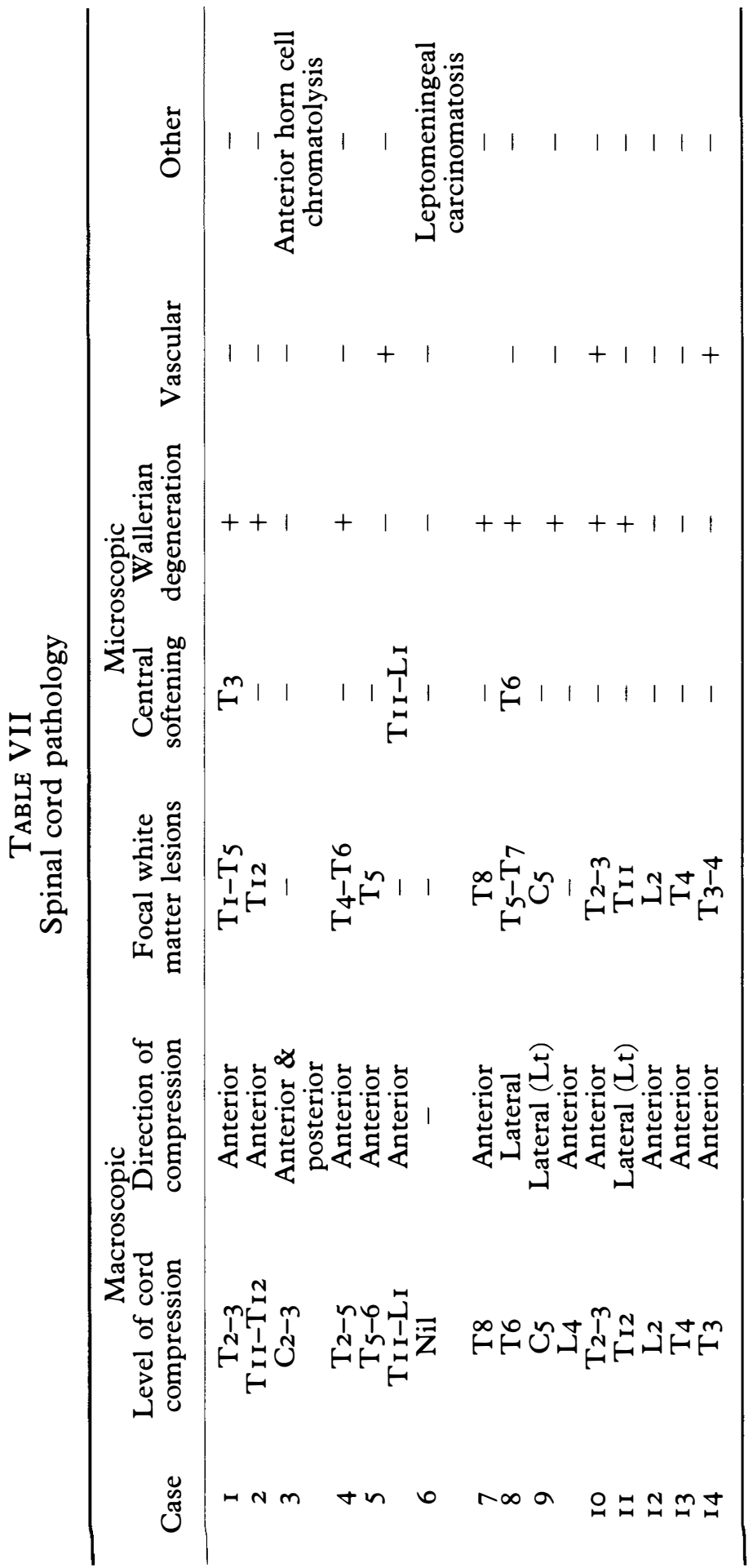


spinal cord was macroscopically normal in Case 6 where there was diffuse leptomeningeal carcinomatosis evident histologically.

Of the three cases with severe softening of the spinal cord, two patients presented with paraplegia of sudden onset following minor trauma. In most cases the anterior surface of the spinal cord was compressed by collapsed vertebral bodies (Fig. 4) or by pedicles infiltrated by tumour or by intervertebral malignant masses bulging posteriorally into the spinal canal. Two cases showed lateral compression. The spinal arteries and veins were carefully examined and they appeared normal.

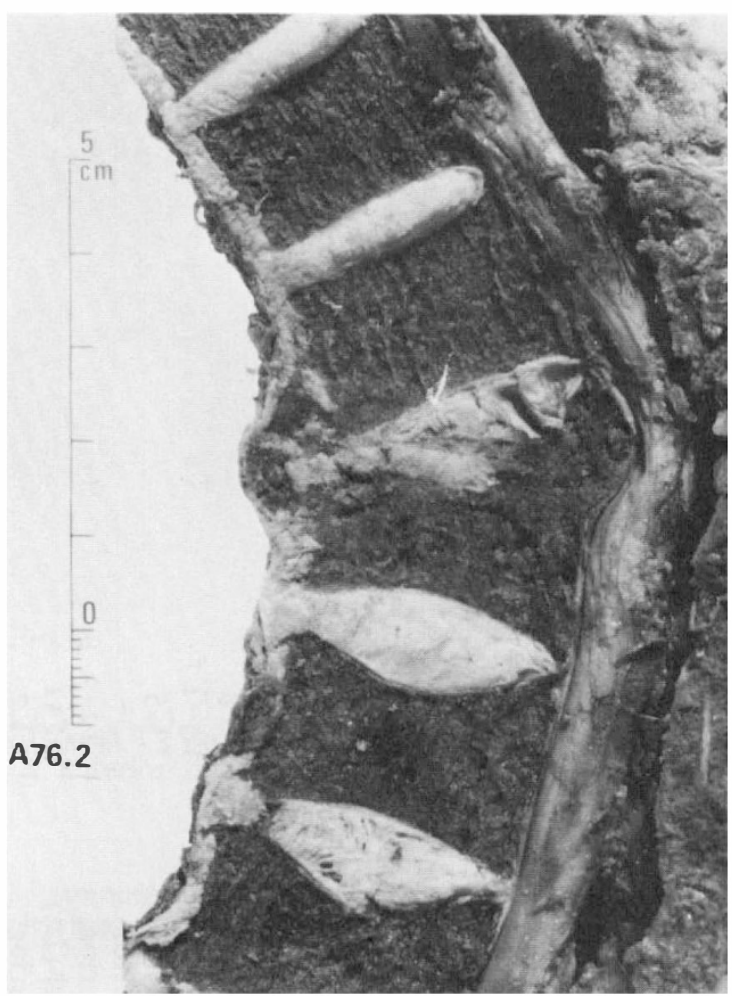

FIG. 4

(Case 7, A76.2) Collapse of T8 vertebra causing anterior compression of the spinal cord and a complete paraplegia.

\section{Microscopic Findings}

The vertebral lesions considered macroscopically to be metastases were confirmed histologically. The most interesting finding in this regard was the intimate relationship between the epidural deposits and the metastatic vertebral lesions. Three of the epidural masses were direct extensions from metastatic tumour within either the body or the pedicles of the vertebrae.

The types of microscopic lesion are listed in Table VII. Twelve of 


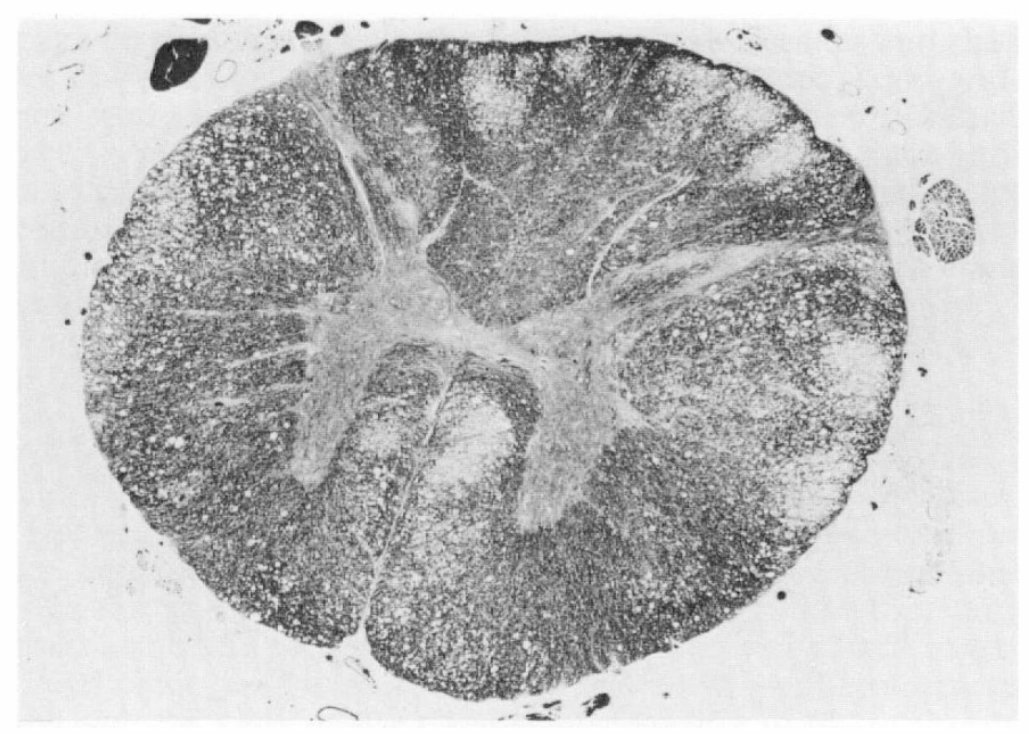

FIG. 5

(Case I I, A76.7I) Peripheral white matter lesions of the spinal cord. Note severe involvement of posterior and lateral columns and relative preservation of anterior columns.

(Haematoxylin and eosin).

the cases showed focal white matter lesions. The lesions tended to be peripheral rather than central (Fig. 5). The central grey matter was generally intact. The lesions were most common in the posterior and lateral columns with relative sparing of the anterior columns. These white matter lesions varied from focal loss of myelin to complete necrosis with destruction of both myelin and axons. The foci were lacy or vacuolated in appearance. Axon retraction bulbs were present in many of the early lesions and in some instances there were inflammatory infiltrates which were either polymorphonuclear or mononuclear depending on the age of the lesion. There were foci of different ages in the same transverse section of the spinal cords in several cases. The foci were sometimes wedgeshaped with the base of the wedge lying on the spinal cord surface. In the most severe cases the foci tended to coalesce resulting in a shrunken segment of cord, the lateral and posterior columns showing a spongy vacuolated appearance. The meninges and large blood vessels appeared normal. However, in three of the 12 cases with focal white matter lesions, several small blood vessels in the spinal cord contained fibrin thrombi. These thrombi stained specifically with the Martius Scarlet Blue stain (Fig. 6). The thrombi showed no evidence of organisation. The occluded vessels were invariably restricted to the white matter but did not appear to be related anatomically to the focal necrotic or demyelinative lesions. There was no specific pattern of distribution of the thrombi. Meningeal vessels were normal. Of the other two cases, one patient had diffuse leptomeningeal carcinomatosis (Case 6). There was no evidence of nerve root degeneration in the sections examined. Peripheral nerves were not examined in this case. Patient no. 3 who suffered a transient tetra- 


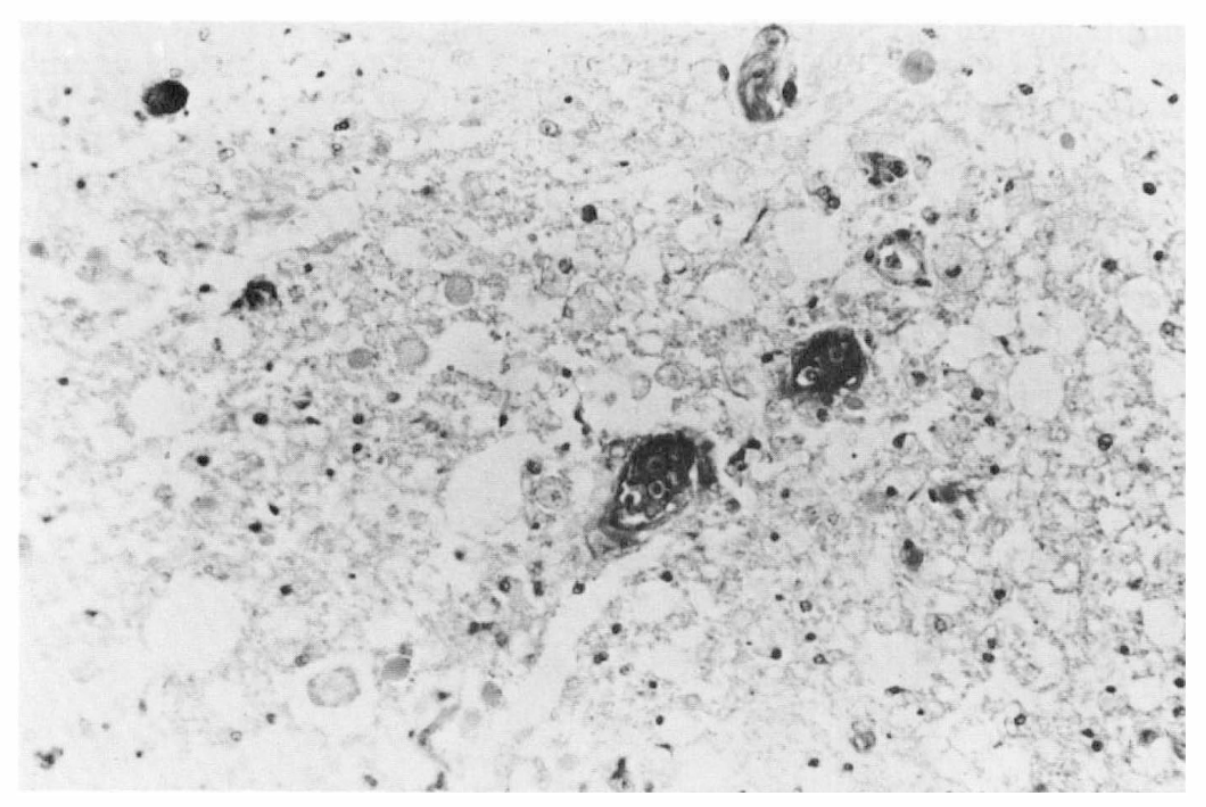

FIG. 6

(Case 5, A76.237) Posterior column showing thrombus within small venule.

(Haematoxylin and eosin).

paresis and recovered completely showed chromatolysis of anterior horn cells in the $\mathrm{C}_{2}-3$ transverse sections examined. This was an acute change and could not be related to her original symptomatology.

In three cases there was central softening of the spinal cord in addition to the focal white matter lesions which tended to be seen most clearly at the extremities of the central necrotic lesion. These lesions were centred in the grey matter rather than the white matter and extended posteriorly to involve the ventral part of the posterior columns and the posterior horns. There was necrosis of both grey and white matter with central cavitation. There were many lipid filled macrophages within the cavities. Wallerian degeneration of the ascending posterior columns and lateral spinothalamic and spino-cerebellar tracts was found in eight cases. Descending lateral cortico-spinal tract degeneration was present in six cases. The severity of the secondary or Wallerian degeneration was related to the severity of the spinal lesion and the length of survival of the patients after the onset of spinal cord compression.

\section{Discussion}

The clinical findings are consistent in this series with previous reports of spinal cord compression and paraplegia due to vertebral metastases (Alexander et al., 1956; Bansal et al., 1967; Botterell and Fitzgerald, 1959; Brice and McKissock, 1965; Dickson, 1968; Kennady and Stern, 1962; Mullan and Evans, I957; Perese, I958; Smith, I965; Torma, I957; Wild and Porter, I963). 
The age distribution was in the fourth to sixth decades and the incidence in males and females was the same. Barron, Hirano, Araki and Terry in I 959 in a study of 127 cases, found that the commonest primary tumours were carcinomas of the lung and breast and lymphomas. Our findings were similar with regard to the carcinomas but no cases related to lymphoma. The commonest presenting symptom was pain, usually in the back. Kennady and Stern (1962) stated that a characteristic spinal symptom was pain in almost all of the I03 cases which they studied. Spinal cord or nerve root compression may also be the presenting feature of the primary tumour, as was the case in four of our patients.

The acuity of onset and the rapidity of progression to complete or incomplete paraplegia was notable in this series, and this was described in previous reports (Arseni, Simionescu and Horwath, 1959; Barron et al., I959; Kennady and Stern, I962; Torma, 1957). This rapid progression has been considered to be due to tumour growth and a high incidence of pathological vertebral fractures. Certainly three of the four patients who developed a sudden paraparesis had suffered a minor back injury and the spinal cord compression was probably related to a collapse fracture.

However, in view of the microscopic finding of fibrin thrombi within small spinal cord blood vessels in three cases and the rather unusual peripheral pattern of lesions in the white matter in 12 of the 14 cases, it is suggested that circulatory disturbances play a part in the progression of the neurological signs.

The importance of epidural metastases as a cause of spinal cord compression has been emphasised by many authors. Batson, in 1942, described the anatomy of the vertebral venous system with its rich, valveless ramifications and connections and suggested the possibility of retrograde spread of tumour emboli into the epidural space via this pathway. This concept was supported by Dinning (196I), Rogers (1957) and Wild and Porter (1963). They explained the apparent predilection of metastases for the epidural space on this hypothesis.

However, the results of this study suggest that the epidural metastases are generally in continuity with vertebral metastases. The actual incidence of isolated epidural metastases may be found to be quite low if the entire vertebral column can be examined at autopsy as described in the methodology herein. We noted that there were metastases in the lungs of nine of these I 4 cases. These included one case of prostatic adenocarcinoma and three intra-abdominal primaries. This suggests that arterial dissemination of metastases is common and is more important than retrograde spread via the vertebral venous plexus. However, it is not denied that metastases may spread via the vertebral venous plexus, particularly from primary carcinomas arising within the pelvis. Experimentally, Coman and DeLong (I95I) have demonstrated that tumour cell suspensions, injected into the femoral veins of rats and rabbits can produce vertebral metastases.

Despite the presence of epidural deposits, there was no direct penetration or invasion of the dura by the tumours. The ease with which epidural metastases can be stripped from the dura mater at operation was emphasised by both Dinning (196I) and Rogers (1957). The exact nature of the protective barrier which the dura mater forms is not understood. It may be that the tumour spreads along lines of least resistance such as within the epidural space. There are venous channels traversing the dura mater but Dinning 
(I96I) suggested that intradural transmission of tumour emboli by this route is unlikely because the intradural venous pressure is higher than the vertebral venous system pressure and flow will be either axial or centrifugal.

Histologically the most common finding in the spinal cord at the level of compression was focal demyelinative or necrotic lesions, which were centred on the white matter columns with relative preservation of the grey matter. These lesions were frequently multifocal and the peripheral areas of the lateral and posterior columns were most severely affected, regardless of the site of maximal compression. The anterior surface of the spinal cord was the most common area of maximal compression. Interestingly, there was relative sparing of the anterior white matter columns.

There was destruction of myelin and subsequently disruption of axons with the formation of axon retraction bulbs. In some instances there was frank necrosis with microcavitation. Despite the relative preservation of the grey matter and the anterior columns, all the cases were clinically transverse spinal cord lesions. This fact is in accord with Barron et al. (1959) who reviewed 127 cases of spinal cord compression by metastatic neoplasms, and pointed out the discrepancies between the clinical symptomatology and signs and the morphologic changes in the spinal cord. McAlhany and Netsky in I955 described very similar changes in their study of I9 cases of compression of the spinal cord by extramedullary neoplasms. They stated that the white matter was more severely damaged than the grey matter in each case.

Concerning the aetiology of these changes, they attributed the white matter lesions to the mechanical effects of the compression and the secondary collapse of small intramedullary blood vessels. As in our cases, the major arteries and veins were normal both macroscopically and microscopically. However, we noted small fibrin thrombi in the small intramedullary vessels in three of the cases. This suggests that thrombosis secondary to continuous compression by epidural masses may be a causative factor in the white matter changes. Similar lesions were shown to occur in spinal phlebitis by Neumayer (1966). McAlhany and Netsky (I955) specifically stated that no thrombi were seen. Sparing of the anterior columns has been observed by other authors. Mair and Druckman (1953) suggested that the white matter lesions were caused by compression of the distal ramifications of the anterior spinal artery, thus sparing the anterior columns. However, this does not explain the preservation of the grey matter. The anterior sulcus may permit greater mobility of this part of the compressed spinal cord and the sulcal vessels may be protected, as was suggested by McAlhany and Netsky (1955).

The cases in which there was severe softening of the spinal cord at the site of compression, with histologic evidence of central grey matter necrosis in addition to the peripheral white matter lesions, may represent a different pathologic process. These lesions closely resemble those seen in traumatic spinal cord injuries. Kakulas and Bedbrook (1976) in their clinicopathological study of injuries of the spine and spinal cord, commented that extension and compression or dispersion injuries were more often associated with haemorrhage and necrosis in the spinal grey matter. This group formed the largest number of clinically incomplete lesions in their study of more than IOO cases. It should be noted that Patient I, who had a central type of lesion, presented with a sudden onset of symptoms following 
minor injuries. The nature of the injury was not ascertained. Vertebral metastases, of course predispose to pathological fractures, which are usually compression in type and these may have given rise to the traumatic type of spinal cord lesion.

The secondary or Wallerian degeneration of the ascending posterior and lateral spino-thalamic and spino-cerebellar tracts and the descending degeneration of the lateral cortico-spinal tracts is identical to that seen in any spinal cord disease which causes interruption of these axonal pathways. This phenomenon is an extremely slow process and histological changes will not be visible until about three weeks after the damage occurs. This delay explains the apparent absence of long tract degeneration in several of the cases.

Laminectomy and decompression has been advocated by many authors as the treatment of choice for paraplegia due to vertebral metastases (Botterell and Fitzgerald, I959; Cole, Godsick and Norman, 1969; Kakulas and Bedbrook, 1976; Love, Miller and Kernohan, 1954; Mullan and Evans, 1957; Smith, I965; Torma, I957; Wild and Porter, I963). However, other authors have disputed the value of laminectomy and have stated that surgery should be directed at pain relief (Arseni et al., I959; Rasmussen, Kernohan and Adson, 1940; Shenkin, Horn and Grant, I945). In this series, half of the patients were subjected to laminectomy and only one of the seven benefitted from the operative procedure. Unfortunately, in only one instance was surgery able to be carried out within 24 hours of the onset of paraplegia. As in any situation with spinal cord compression, regardless of the aetiology, the time factor is critical. Barron et al. (1959) suggested certain indications and contraindications for surgery. They stated that patients with a spastic paraplegia have a better prognosis than those with a flaccid paralysis. Patients with metastases from carcinoma of the lung had a uniformly unfavourable prognosis. Other forms of treatment have been suggested and these include laminectomy followed by irradiation (Arseni et al., 1959; Rasmussen et al., 1940; Wild and Porter, 1963). These authors also stated that even minimal neurological improvement is sufficient justification for surgery.

However the possible complications of laminectomy must not be overlooked. The most frequent and serious problem following laminectomy in this series was the impaired stability of the spine at the laminectomy site. Bucy (1963) emphasised this problem and described the metal implant used by Kryaenbuhl to correct the spinal deformity and support the vertebral column. Similar techniques have been reported by Halnan and Roberts (1967); Martin and Williamson (1970); Cross, White and White (I97I) and Wienand (I97I). Patient II in this series had a very unstable spine after laminectomy, but stability was obtained by resecting the collapsed vertebral body and replacing this with acrylic bone cement. This technique was previously reported by Harris in I96I; then by Silverstein in I97I. The anterior approach, as described by Halnan and Roberts (1967) should perhaps be considered more often as the spine retains greater stability.

\section{RÉSUMÉ}

L'interêt clinique porté à la compression vertébrale et à la paraplégie consécutive, due aux métastases, s'est accru ces dernières années. Ceci a encouragé l'attentation à se porter sur 
la neuropathologie du patient. On a comparé i 4 cas de compression de la moëlle épinière causée par des métastases vertébrales avec plus de roo cas traumatiques. Dans les lésions traumatiques, on observe une nécrose hémorragique centrale qui entraine une cavitation et une gliosis avec régénération de la racine nerveuse dans les dernières phases de la maladie. Dans les cas métastatiques, les lésions sont souvent périphériques, de forme circulaire et sont liées à des facteurs vasculaires. La neuropathologie de la nécrose de la moëlle épinière due à une maladie métastatique vertébrale est donc différente du traumatisme. Ces observations ont une importance clinique dans l'établissement due traitement.

\section{ZUSAMMENFASSUNG}

Klinisches Interesse an Rückenmarkkompression und entstehende beiderseitige Lähmung infolge Versetzungen der Krankheitsstoffe (Metastases) ist in den letzten Jahren gewachsen. Dieses hat die Aufmerksamkeit auf die Neuropathologie des Zustandes gelenkt. Vierzehn Fälle von Rückenmarkkompression infolge Versetzungen der Krankheitsstoffe in der Wirbelsäule sind mit über roo traumatischen Fällen verglichen. In traumatischen Verletzungen trit zentrale Blutsturznekrose auf, die zu Höhlungen und Gliosis mit Regeneration der Nervenwurzel in fortgeschrittenen Stadien führt. In den metastatischen Fällen sind die Verletzungen oft peripherisch, rundlich und stehen in Bezug zu gefässförmigen Faktoren. Die Neuropathologie der Marknekrose, verursacht durch metastatische Rückenmarkkrankheit ist deshalb verschieden von dem Trauma. Diese Feststellungen sind von klinischer Wichtigkeit in der Behandlungsplanung.

\section{REFERENCES}

Alexander, E. Jr., Davis, C. H. JR. \& Field, C. H. (I956). Metastatic lesions of vertebral column causing cord compression. Neurology (Minneap), 6, I03-107.

Arseni, C. N., Simionescu, M. D. \& Horwath, L. (I959). Tumours of the spine. Acta psychiat. scand., 34, 398-4IO.

Bansal, S., Brady, L. W., Olsen, A., Faust, D. S., Osterholm, J. \& Kazen, I. (I967). The treatment of metastatic spinal cord tumours. F. Amer. med. Ass., 202, 686-688.

Barron, K. D., Hirano, A., Araki, S. \& Terry, R. D. (I959). Experiences with metastatic neoplasms involving the spinal cord. Neurology (Minneap), 9, 91-Io6.

Batson, O. V. (1942). Role of vertebral veins in metastatic processes. Ann. intern. Med., I 6, 38-45.

Botterell, E. H. \& Fitzgerald, G. W. (I959). Spinal cord compression produced by extradural malignant tumours. Early recognition, treatment and results. Canad.med. Ass. F., 80, 79I-794.

BRICE, J. \& MCKISSOCK, W. (I965). Surgical treatment of malignant extradural spinal tumours. Brit. med. F., I, I339-1342.

Bucy, P. C. (I963). The treatment of malignant tumours of the spine: A review. Neurology (Minneap), 13, 938-944.

Cole, S. C., Godsick, P. A. \& Norman, A. (1969). The value of laminectomy in benign and malignant extradural spinal cord compression. Bull. Hosp. Ft. Dis., 30, 76-80.

Coman, D. R. \& DELong, R. P. (I95I). The role of the vertebral venous system in the metastasis of cancer to the spinal cord. Experiments with tumour-cell suspensions in rats and rabbits. Cancer (Philad), 4, 610-6I8.

Cross, G. O., White, H. L. \& White, L. P. (I97I). Acrylic prosthesis of the fifth cervical vertebra in multiple myeloma. $\mathcal{F}$. Neurosurg., 35, I I 2-I I 4.

Dickson, J. W. (I968). Surgical treatment of paraplegia due to extradural spinal metastases. Proc. roy. Soc. Med., 61, 553-555.

Dinning, T. (I96I). Malignant spinal extradural tumours. Aust. N.Z. F. Surg., 31, 1 26I33.

Halnan, K. E. \& Roberts, P. H. (1967). Paraplegia caused by spinal metastasis from thyroid cancer. Brit. med. F., 3, 534-536.

HARris, P. (I96I). The Uses of Methyl Methacrylate in Neurosurgery. International Congress Series. Excerpta Medica., 36, E8I.

Kakulas, B. A. \& Bedbrook, G. M. (1976). Pathology of injuries of the vertebral column with emphasis on the macroscopical aspects. Handbook of Clinical Neurology, 25, 2742, North Holland Publishing Co., Amsterdam.

KenNaDy, J. C. \& STERN, W. E. (I962). Metastatic neoplasms of the vertebral column producing compression of the spinal cord. Amer. F. Surg., 104, I 55-168. 
Love, J. G., Miller, R. H. \& Kernohan, J . W . (1954). Lymphomas of the spinal epidural space. A.M.A. Arch. Surg., 69, 66-76.

MaIR, W. G. P. \& DRUCKMAN, R. (I953). The pathology of spinal cord lesions and their relation to the clinical features in protrusion of cervical intervertebral discs. A report of four cases. Brain, 76, 70-91.

Martin, N. S. \& Williamson, J. (I970). The role of surgery in the treatment of malignant tumours of the spine. F. Bone Ft. Surg., 52B, 227-237.

McAlhany, H. J. \& Netsky, M. G. (I955). Compression of the spinal cord by extramedullary neoplasms. F. Neuropath. Exp. Neurol., 14, 276-287.

Mullan, J. \& Evans, J. P. (I957). Neoplastic disease of the spinal extradural space. A review of fifty cases. Arch. Surg., 74, 900-907.

Neumayer, E. (1966). Spinal phlebitis. Dtsch. Z. Nervenheilk., 189, 87-103.

PERESE, D. M. (1958). Treatment of metastatic extradural spinal cord tumours. A series of 30 cases. Cancer, II, 214-221.

Rasmussen, T. B., Kernohan, J. W. \& Adson, A. W. (1940). Pathologic classification with surgical consideration of intraspinal tumours. Ann. Surg., III, 513-530.

Rogers, L. (1957). Malignant spinal tumours and the epidural space. Brit. F. Surg., 45, $416-422$.

Shenkin, H. A., HoRn, R. C. JR. \& GRANT, F. C. (1945). Lesions of spinal epidural space producing cord compression. Arch. Surg., 51, I25-I 46.

SilverSTEIN, E. (I97I). Stabilisation of spinal instability from metastatic carcinoma with surgical simplex. F. Bone ft. Surg., 53B, I 58.

SMITH, R. (1965). An evaluation of surgical treatment for spinal cord compression due to metastatic carcinoma. F. Neurol. Neurosurg. Psychiat., 28, I 52-1 58.

Torma, T. (1957). Malignant tumours of the spine and the extradural space. Acta chir. scand. Suppl., 225, I-I 76.

WIENAND, A. J. (I97I). Anterior decompression for tumours of the vertebral bodies. $\mathcal{F}$. Bone ft. Surg., 53B, 563-564.

Wild, W. \& PORTER, R. (1963). Metastatic epidural tumours of the spine. Arch. Surg., $87,825-830$. 